\title{
Seventeen years' experience of a voluntarily based drug rationalisation programme in hospital
}

\author{
John A Baker, Ariel F Lant, Carol A Sutters
}

\begin{abstract}
A study was carried out analysing the operation of a drug rationalisation programme in a central London teaching district that had evolved from experience over 17 years. Creation of a limited list of about 700 drugs had been achieved by local consensus. Drug selection was based on appraisal of efficacy, safety, and cost and was undertaken by means of collaborative participation of most consultant specialists in the district. Educative and other non-restrictive strategies for reinforcing the rationalisation policy had achieved a consistently high rate of compliance in prescribing recommended drugs. The concept of selectivity in drug use and its continuous local reappraisal had a beneficial impact on the prescribing habits of doctors at all levels of seniority as well as on the training of medical undergraduates and nurses in the therapeutic use of medicines. Peer review and self audit were encouraged by use of an extensive monitoring system which incorporated continuous "facilitative" dialogue between ward pharmacists and prescribers. Two models of drug rationalisation programme were studied, the second of which together with other local initiatives had been associated with substantial and sustained reductions in drug spending each year over nine years since 1978 .
\end{abstract}

It is concluded that the second drug rationalisation programme model substantially improves the cost effective use of drugs in hospital and furthermore has the potential of being extended to general practice, especially in types of prescribing that are common to both forms of patient care.

\section{Introduction}

Doctors continue to have difficulty in making rational decisions when choosing what they believe is the best treatment for their patients. ${ }^{1-4}$ Inappropriate prescribing is usually a result of inadequate knowledge and confused motives. ${ }^{56}$ Over the past 20 years the information on new drugs has increased so much that it often overwhelms the practising clinician. The need for doctors to assess and improve the quality and efficiency of health care is widely recognised, ${ }^{7-9}$ yet it has repeatedly been asked whether a doctor really has the right "to prescribe what he likes to whom he likes for as long as he likes." 10 As a large part of patient management entails the use of medicines, resulting in a yearly national drugs bill of $£ 1.4$ billion, attention has been directed at the need to encourage more rational prescribing. ${ }^{11}$

Methods for controlling prescribing in Britain have been debated for well over 10 years. ${ }^{12.14}$ Nationally restricted prescribing lists have been operated successfully in several countries, not always without controversy. ${ }^{15-18}$ Within the National Health Service recent government policies have been preoccupied primarily with the economics rather than the quality of prescrib- ing, and in 1985 a "black list" imposed central limitation on certain categories of drugs available within the NHS. An alternative approach to central limitation is a local approach brought about by consensus. With the emergence of drug and therapeutic committees in most hospitals in Britain ${ }^{1920}$ greater emphasis has been placed on the production and adoption of local hospital formularies. ${ }^{21-25}$ There have been several anecdotal accounts of the composition of these formularies, but their impact has not been thoroughly evaluated; improved prescribing, however, has been claimed. ${ }^{25}{ }^{26} \mathrm{~A}$ parallel development has occurred in community based medical practice..$^{27-29}$ These initiatives have been encouraged..$^{30}{ }^{31} \mathrm{We}$ present an account of our experience over the past 17 years.

\section{Methods}

CREATION OF WESTMINSTER FORMULARY:

INITIAL MODEL, 1970-8

The central feature of our drug rationalisation programme was the creation of a locally agreed limited list or formulary. In January 1970 two of us (JAB and AFL) were asked to join a working party of the board of governors of Westminster Hospital to investigate methods for curtailing rising drug expenditure. It was thought that drug costs could best be controlled by introducing a formulary containing a limited selection of drugs relevant to hospital practice.

A specially appointed formulary subcommittee of the medical executive committee was given responsibility for preparing the limited list. The formulary, which fulfilled an educational role by providing essential information on selection and use of medicines, was issued in sections as each therapeutic category was completed. Within those specialties covered by the formulary hospital pharmacies restricted stocks to approved items. When a non-formulary item was prescribed the prescriber was contacted by a pharmacist who suggested an approved alternative, but if the clinician confirmed the request a record was kept in the pharmacy and a limited supply of the drug obtained, inevitably with some delay.

The subcommittee functioned as shown in figure 1 (formulary based model) but proved cumbersome, as it lacked the flexibility to allow rapid revision of the formulary. The result was that increasing numbers of non-formulary items had to be stocked to meet changing prescribing needs. We were thus faced with a model that could not adapt swiftly to clinical needs or respond efficiently to the worsening financial climate in the NHS. These defects led to the evolution of an alternative model.

TRANSITION FROM FORMULARY TO DISTRICT DRUGS GUIDE: SECOND RATIONALISATION MODEL, 1978 TO DATE Characteristics of system

Five unique features characterised the new model (Fig 1; drugs guide model). Firstly, the system
Ariel F Lant, FRCP, professor of clinical pharmacology

Correspondence to: Professor Lant. 
Formulary based model

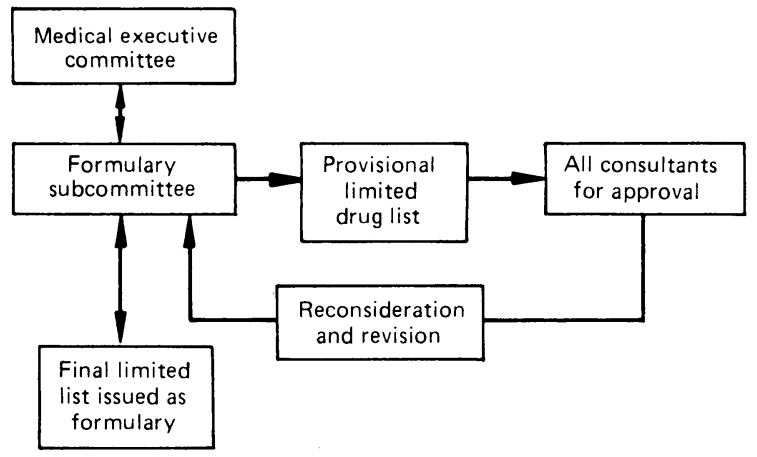

Drugs guide model

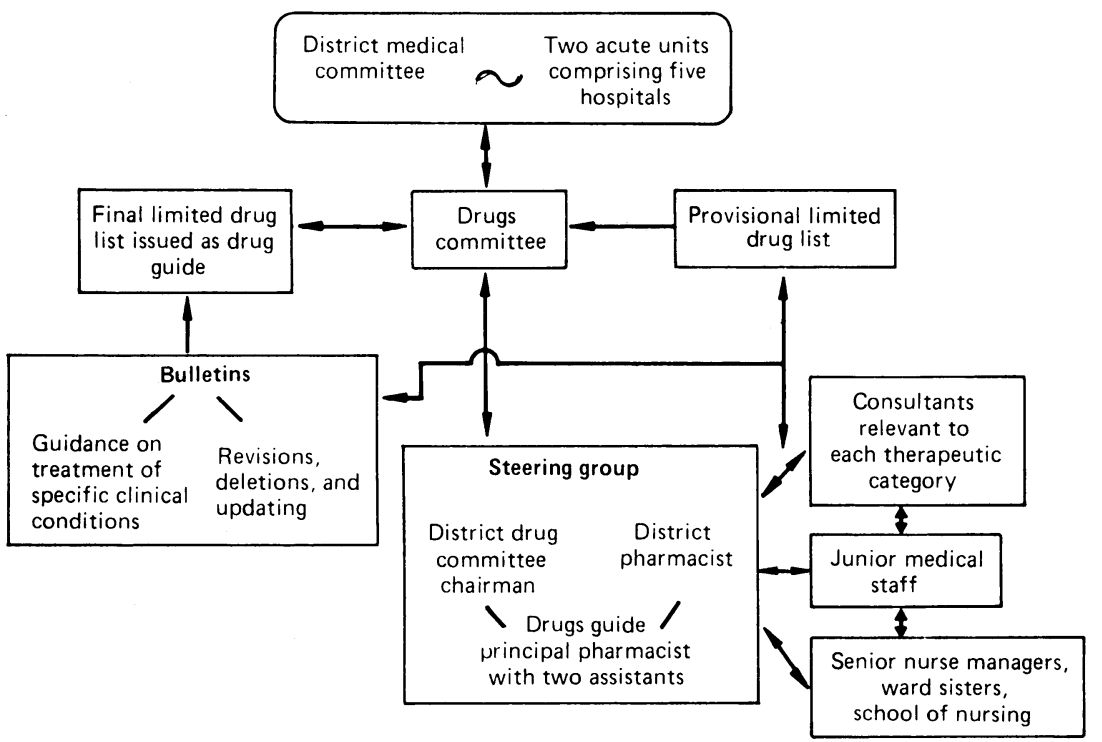

FIG 1-Diagrammatic representations of formulary based model and drugs guide model of drug rationalisation
A structured mechanism for monitoring was set up through hospital pharmacy departments by using the ward pharmacy network. The four dispensaries in the district all operated in the same way. Pharmacists contacted the prescriber whenever a non-guide drug was prescribed and asked whether an alternative product listed in the guide had been considered. A written record of the exchange was kept. When the prescriber expressed a specific wish to use a drug not in the guide this was noted without comment, though a record of usage was maintained. Alterations to prescriptions were never imposed. Patients admitted to hospital taking maintenance doses of drugs not included in the guide were encouraged to continue with their treatments unless change was deemed appropriate on clinical grounds.

Every three to six months each consultant received a summary of non-guide prescribing by members of the relevant clinical team. This identified the potential need for change in agreed drug policies. The location of members of the steering group was split between the two acute units to encourage regular personal contact with all grades of medical, nursing, and pharmacy staff working at different geographic sites. This helped communication and the monitoring of the rationalisation policies.

\section{Results}

COLLABORATION AMONG HEALTH PROFESSIONALS

The drug rationalisation programme was found to be effective in building and strengthening relationships among staff in different hospital departments. The process of preparing and updating the drugs guide established a working infrastructure which the drugs committee was able to direct. When specific matters of uncertainty occurred small multidisciplinary teams were set up to debate the issues and produce recommendations for the drugs guide. The appendix lists the range of topics tackled by these special teams.

\section{COMPLIANCE}

The continuous monitoring system enabled us to make regular assessments of compliance with prescribing policies (fig 2). At the time of introduction of the drugs guide in 1979 the impact of the previous formulary was already evident. Only about 200 prescriptions $(1 \cdot 2 \%)$ of a monthly total of 17000 were for items not in the guide. Within six months this figure had fallen to about $80(0.5 \%)$; a smaller rise to around $160(0.9 \%)$ followed, coinciding with the appointment of new house officer staff. There were similar cyclical patterns after all successive editions of the guide. These reflected the reinforcing influences of the special seminars for each batch of newly appointed house staff and the influence of direct discussion between the prescriber and pharmacy staff whenever a non-guide item was prescribed. Roughly one fifth of the already low percentage of non-guide prescribing was further altered voluntarily as a result of these discussions (fig 2 ). At the time of reporting, with a total of 700 drugs in the guide, the monthly level of compliance was consistently over $99 \%$.

\section{EDUCATIONAL IMPACT}

High compliance with policies in the drugs guide implied that a substantial educational influence on prescribing had been achieved. This was studied more specifically by examining prescribing patterns in relation to popular groups of drugs. Over two months in 1984 all treatments with broad spectrum penicillins related to ampicillin were surveyed in one acute unit. Of 1220 courses of antimicrobials given to 753 patients during the survey period, $263(21 \cdot 6 \%)$ were for one of undergraduate medical students and nurses training in the district attended regular lectures and seminars on the aims and working of the system and all received a copy of the drugs guide. 
the broad spectrum penicillins. Of these, $239(91 \%)$ were for ampicillin, the only member of the group included in the drugs guide. The numbers of courses of treatment with other antibiotics in this category were $5(2 \cdot 1 \%)$ for amoxycillin, $18(7 \cdot 5 \%)$ for mezlocillin, and $1(0 \cdot 4 \%)$ for clavulanic acid.

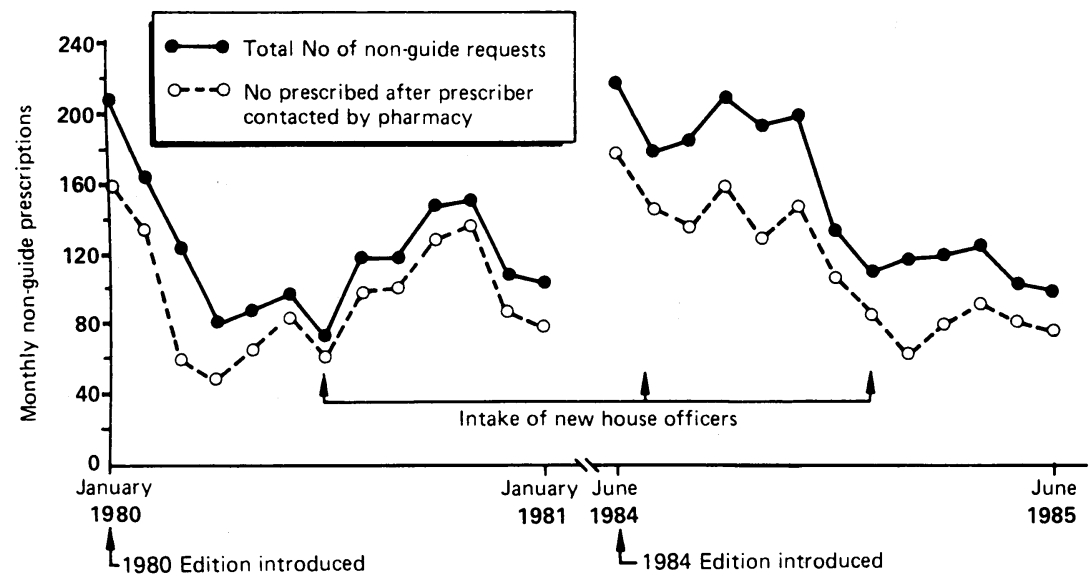

FIG 2-Monitoring of non-guide requests over two separate 12 month periods showing similar cyclical patterns after issue of new editions of drugs guide. Total number of prescriptions in Riverside East was roughly $200000 / y e a r ;$ thus total monthly number of non-guide prescriptions of about 200 indicates compliance of approximately $99 \%$ )

In a second survey in 1986 usage of non-steroidal anti-inflammatory drugs was studied during the month before and in the fourth month after rationalisation of these agents in the district. Before rationalisation $67(14 \%)$ of a total of 479 prescriptions a month were for non-guide products, whereas after rationalisation the equivalent figure was $29(9 \%)$ of a total of 318 prescriptions. This resulted in a fall in total district expenditure on non-steroidal anti-inflammatory drugs of $12 \%$ over six months-that is, from $£ 25000$ to

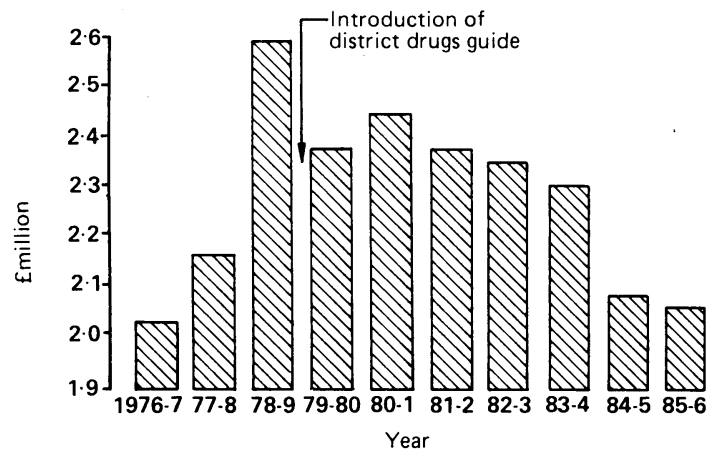

FIG 3-Yearly expenditure on drugs in Riverside East (previously Victoria) District over 10 years 1976-86. All figures adjusted to Department of Health and Social Security's Hospital Service Price Index, November 1985, which incorporates adjustments for inflation. (Over the 10 years total number of deaths and discharges within Riverside East ranged from $30 \cdot 0 \times 10^{3}$ to $31 \cdot 8 \times 10^{3} /$ year
$£ 22000$ over the whole year. The reduction in total usage of non-steroidal anti-inflammatory drugs was specially noticeable in the accident and emergency department, where particular effort had been directed at encouraging junior medical staff to be more selective in their prescribing.

\section{FINANCIAL IMPACT}

Despite several important administrative reorganisations of the NHS during the study period, the functional integrity of the hospitals within the district made it possible to keep track of the yearly spending on drugs. Figure 3 shows that during the years leading up to the issue of the first edition of the drugs guide expenditure on drugs was rising in our district by $10-15 \%$ a year, as was the average yearly rise in hospital drug expenditure in the mid to late 1970s. These trends showed that the initial formulary system was not containing drug expenditure. The fundamental redesign of the working model culminated in the issue of the District Drugs Guide in 1979. In each successive year after 1979 expenditure on drugs either fell or was held stable despite the release and approved use of several very expensive new drugs. The maximum reductions achieved lay between $£ 0.8 \mathrm{~m}$ and $£ 1.0 \mathrm{~m}$ a year. During the same 10 year period the total number of patients treated in the district, as reflected in total deaths and discharges, remained static at about 31000 a year. There were minimal changes in the total number of prescribers.

In 1984 we requested data on drug expenditure from all London teaching districts over the previous four years. During that time no other district had a fully operational drug rationalisation policy. Of the eight districts that replied, one was discounted because of the closure of a central London acute unit. The findings showed an average yearly increase of $3 \%$ for each of six districts, the remaining district having kept its spending constant; our district had a consistent yearly decrease of $2 \%$.

Our sustained reduction in drug expenditure might have been a direct result of the substantial drop in the total number of drugs held in stock. Some of the most striking curtailments were made in the categories within which the government imposed its national blacklist in 1985, such as antacids, laxatives, and hypnotics (table I). The relative contribution to drug expenditure is not, however, determined only by the number of products retained within a given class or even by their frequency of usage; the inherent cost of individual products is also very important (table II).

Besides the reduction in stock other initiatives which undoubtedly contributed to the overall financial savings were reductions in the volume of prescribing for outpatients, better control of drug wastage, and better performance in procuring drugs at competitive prices.

TABLE I-Important changes in drug recommendations within specified therapeutic categories in drugs guide together with corresponding alterations in pattern of usage as shown by yearly expenditure before and after individual substitutions

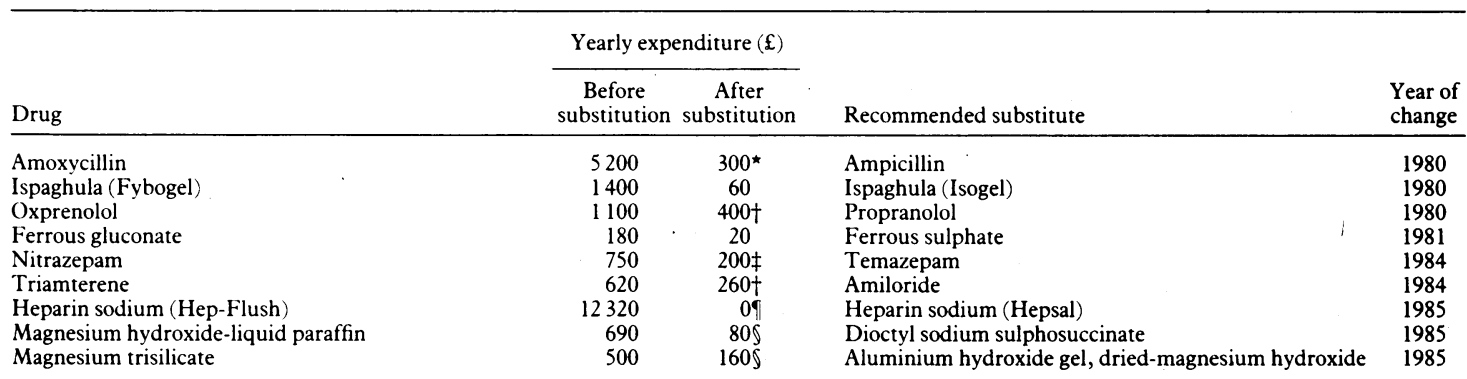

ॠTwo clinical specialties (ear, nose, and throat and paediatrics) retained substantial use of amoxycillin.

†Figure reflects proportion of patients previously stabilised on primary treatment who continued with drug.

$\ddagger$ Nitrazepam retained in guide but regarded as second choice to temazepam for routine use.

§Product retained in obstetrics.

†Use of Hep-Flush totally discontinued; introduction of Hepsal led to yearly expenditure on this product of $£ 7000$. 
TABLE II-Drugs in selected therapeutic categories in Riverside East drugs guide and British National Formulary $(B N F)^{\star}($ Figures for expenditure show extent of compliance with locally agreed limitations and rationalisations and at same time reflect continued use of certain nonguide treatments initiated in the community or at another hospital outside district)

\begin{tabular}{|c|c|c|c|c|c|}
\hline \multirow[b]{3}{*}{ Drug class } & \multicolumn{3}{|c|}{ No of drugs: } & & \\
\hline & \multicolumn{2}{|c|}{ Recommended $\dagger$} & \multirow{2}{*}{$\begin{array}{c}\text { Blacklisted } \\
\text { in } B N F \ddagger\end{array}$} & \multicolumn{2}{|c|}{ Expenditure $1985-6 \S(£)$} \\
\hline & Drugs guide & $B N F$ & & Total & Non-guide (\%) \\
\hline Penicillins (including combinations) & 10 & 28 & - & 81143 & $6843(8.4)$ \\
\hline Cephalosporins & 6 & 14 & - & 97872 & $658(0.7)$ \\
\hline Diuretics (including combinations) & 15 & 50 & - & 24304 & $871(3.6)$ \\
\hline$\beta$ Blockers (including combinations) & 8 & 33 & - & 7825 & $712(9 \cdot 1)$ \\
\hline Antacids (including combinations) & 6 & 60 & 22 & 10374 & $17(0 \cdot 2)$ \\
\hline \multicolumn{6}{|l|}{ Non-narcotic analgesics and non-steroidal anti-inflammatory agents } \\
\hline (including combinations) & 18 & 123 & 43 & 28878 & $3575(12 \cdot 4) \|$ \\
\hline Hypnotics & 12 & 27 & 13 & 14393 & $535(3 \cdot 7)$ \\
\hline Anticonvulsants & 10 & 15 & - & 8271 & $94(1 \cdot 1)$ \\
\hline Antitussives, expectorants, and nasal decongestants (including combinations) & 8 & 74 & 52 & 1562 & $25(1 \cdot 6)$ \\
\hline Laxatives (including rectal preparations) & 19 & 62 & 26 & 42147 & $517(1 \cdot 2)$ \\
\hline Disinfectants ${ }^{\star \star}$ (including topical agents) & 22 & 58 & - & 72009 & $1827(2 \cdot 5)$ \\
\hline
\end{tabular}

*British National Formulary No 15 (1988)

†For drug classes not covered by blacklist generic names and combinations are shown; for drug classes covered by blacklist each entry for drug in $B N F$ was counted and corresponding products or forms counted in guide.

fFigures indicate total number of products and forms blacklisted. In some cases only one strength of product is blacklisted.

FFigures indicate total number of products and forms
§Represents values of issues from stores departments.

ๆ Agreed use of amoxycillin (non-guide preparation) in two clinical specialties accounted for almost all non-guide expenditure in prescribing of penicillins. $\|$ Figures represent expenditure for one year after rationalisation in mid-1986. Usage of mefenamic acid, a non-guide non-steroidal anti-inflammatory agent, was allowed to continue unchallenged for six months after rationalisation so that stocks could be used up.

$\star \star$ In dealing with disinfectants $B N F$ primarily concentrates on anti-infective skin preparations, whereas drugs guide includes broader classification covering disinfectants used in ward areas and operating theatres. In neither case are antiseptics for oropharyngeal or vaginal use included.

\section{Discussion}

Several strategies have been invoked to try to improve the standards, with which drugs are applied to therapeutic practice. ${ }^{32}$ An environment in which the costs of health care spiral upwards all the time tends to highlight the importance of economic factors and encourages the imposition of restrictions. That a power strategy can readily influence prescribing is well shown by the British government's decision in 1984 to introduce a blacklist of drugs in certain categories that would no longer be prescribable within the framework of the NHS. ${ }^{33}$ Such central restriction does not necessarily lead to better prescribing. Indeed, arguably the reverse might occur, as by restricting the use of comparatively innocuous and cheap agents like antacids, for example, inappropriate use of $\mathrm{H}_{2}$ receptor antagonists would increase.

Many factors that influence the decision to prescribe and the choice of agent prescribed remain undefined. ${ }^{3+}$ Prescribing any medicine is a complex process which is both highly individualised and dynamic, subject to social, cultural, and marketing forces. ${ }^{35}$ The process of drug utilisation review, which gives feedback about personal prescribing patterns to the clinician, offers a way of relaying information which has been subjected to peer judgment and can improve the quality of care. It can achieve this, however, only if the prescriber recognises that there is a problem and is willing to change his or her prescribing habits.

Our experience supports the view that a drug restriction policy created voluntarily after local negotiation is most likely to succeed in the long term on both clinical and economic grounds if a number of fundamental criteria are fulfilled. Firstly, the system must be flexible enough to be adapted quickly to new developments and thereby meet the ongoing needs of both doctor and patient. Secondly, willingness to accept change is more likely when an attitude of mutual trust and respect has been generated between those seeking change and the prescriber. Thirdly, participation of the prescriber in the process of drug evaluation is crucial, both at the stage of initial selection and at each stage of reassessment or review.

A key factor operative in our district drugs policy has been termed a "facilitative" influence by Plumridge. ${ }^{32}$ This lays emphasis on personal contact between individuals to encourage two way discussion and consumer feedback. It undoubtedly engenders a commitment to change and has been one of the main tasks undertaken with considerable success by ward pharmacists in our district as part of the routine monitoring of the drugs guide policy. It thus appears valid to argue that educational measures combined with active feedback can have an important influence on clinical behaviour, ${ }^{36}$ whereas each strategy on its own may either have no effect $^{3738}$ or fail to produce sustained change over a long period..$^{39}$

Finally, for a locally restricted drugs list to function in the long term as opposed to the short term the corporate body of prescribers must have the capacity and the desire to be both educated and re-educated. This means both acquiring new knowledge and habits as well as relearning already acquired knowledge and when necessary discarding old attitudes and practices. In a strictly hierarchical system of hospital medical practice, as in Britain, this is not particularly easy. We have relied heavily on stimulating a dynamic personal interchange, which has at times meant senior clinicians influencing one another and at other times junior doctors re-educating their seniors; but, most important, we have sought to harness the professional skills and capabilities of other relevant health professionals as catalysts, notably hospital pharmacists. The need to strengthen interprofessional relationships between pharmacists and clinicians was particularly highlighted in the Nuffield Foundation report on pharmacy. ${ }^{40}$

Our experience to date shows that a limited drug list produced by local consensus as part of a broadly based drug rationalisation policy can successfully influence prescribing habits, improve the quality of patient care, fulfil an educational role for all levels of staff, act as a cohesive link between health professionals, and at the same time appreciably reduce expenditure on drugs in the long term. Even after 17 years of experience we recognise that a substantial challenge remains for the years ahead if the goals of rational and cost effective prescribing achieved so far are to be maintained. The effort would be all the more worth while if our hospital based experience could successfully be extended to general practice within our district and other community units, as so much modern therapeutics is common to both types of patient care. Furthermore, there surely must be much common ground in locally agreed restricted prescribing lists that considerably more sharing of experience could occur between neighbouring health districts and those further afield than occurs at present. 
We thank the many clinicians and pharmacists who have given unsparingly of their time to contribute to the success of the collaborative effort in setting up and maintaining our drug rationalisation programme. We are especially grateful to $\mathrm{Mr}$ D P F Begley, South District management team and Victoria District Health Authority (1975-85); Mr H I Wickings, Westminster Hospital (1971-4); Mr A R Wilson, the firs incumbent of the post of district drugs guide pharmacis (1978-80); and Miss Gwenette Wason for typing the manuscript.

\section{Appendix}

Examples of clinical services policies and therapeutic projects covered by multidisciplinary working teams set up under direction of drugs committee steering group ${ }^{\star}$

\begin{tabular}{ll}
\hline Clinical services policies & Therapeutic projects \\
\hline (a) Intravenous administration of & (a) Antiemetics in cancer \\
drugs & chemotherapy \\
$\begin{array}{ll}\text { (b) Intravenous nasogastric equipment } & (b) \text { Theophylline in asthma } \\
\text { (c) "Nil by mouth" procedures } & (c) \text { Antimicrobial prophylaxis in } \\
\text { (d) Prescription charts and forms } & \text { surgery } \\
\text { (e) Enteral and parenteral feeding } & (d) \text { Treatment of pressure sores } \\
\text { (f) Emergency drug boxes and } & (\text { e) Analgesia in terminal care } \\
\text { contents } & (f) \text { Management of pregnant } \\
\text { (g) Rationalisation of diagnostic } & \text { diabetics; surgery in diabetics } \\
\text { agents used in wards and outpatient } & (g) \text { Management of anaphylaxis } \\
\text { departments } & (h) \text { Management of }\end{array}$ \\
& hypercalcaemia
\end{tabular}

* Topics either had direct relevance to drug policies affecting clinical service or represented controversies in therapeutics that staff considered needed unified recommendation for patient management.

1 Maronde RF, Lee PV, McCarron MM, Seibert S. A study of prescribing patterns. Med Care 1971;9:383-95.

Kunin CM, Tupasi T, Craig WA. Use of antibiotics. A brief exposition of the problem of some tentative solutions. Ann Intern Med 1973;79:555-60.

3 Jackson G, Mahon W, Pierscianowski TA, Condon J. Inappropriate antihypertensive therapy in the elderly. Lancet 1976;ii: 1317-8.

4 Schollenberg E, Albritton WL. Antibiotic misuse in a pediatric teaching hospital. Can Med Assoc $\mathcal{F}$ 1980;122:49-52.

5 Spector R, Roberts RJ. Physician education and drug therapy. $7 \mathrm{Clin}$ Pharmacol 1983;23:491-3.

6 Anonymous. Freedom to prescribe-in ignorance [Editorial]. $\mathrm{Br} \mathrm{Med} \mathrm{f}$ 1978;i:1573-4.

7 Duncan A. Quality assurance: What now and where next? $\mathrm{Br}$ Med $\mathrm{f}$ 1980;280:300-2.

8 Mooney GH, Ludbrook A. The NHS: efficiency need not be a dirty word. BrMed J 1984;288:1817-8.

9 Spoor C, Mooney G, Maynard A. Teaching health economics. Br Med $\mathcal{J}$ $1986 ; 292: 785$

10 Anonymous. The right to prescribe [Editorial). Lancet 1976;ii:351-2.

11 Greenfield Working Party. Report to the Secretary of State for Social Services of the Informal Working Group on Effective Prescribing. London: DHSS, 1982. (Chairman P R Greenfield .
12 McCarthy MJ. Prescribing: a programme emphasising benefits. Lancet 1974 ;ii: $639-40$

13 Anonymous. Second opinion. Should GPs have to prescribe from an approved drug list: [Editorial]. MIMS Magazine 1979; Nov 1:5-7.

4 Yellowlees H. Cutting the drug bill. Br Med f 1980;280:797.

15 Bakke OM. Drug selection in a regulated society. The Norwegian experience. Hospital Formulary 1984;19:411-21.

16 Andrews PR. Should Australia run drugs? Med f Aust 1984;141:324-5.

17 Chew R, Smith GT, Wells N. The economic and political environment. Pharmaceuticals in seven nations. London: Office of Health Economics, 1985:36-49.

18 Smith T. Limited lists of drugs: lessons from abroad. Br Med J 1985;290: 533-4.

19 Brown AW, Barrett CW, Herxheimer A. Hospital pharmacy committees in England: their structure, function, and development. $\mathrm{Br}$ Med $\mathcal{F}$ 1975; 323-5.

20 George CF, Hands DE. Drug and therapeutics committees and information pharmacy services: the United Kingdom. World Development 1983;11: 229-36.

21 Middlebrook MJ. The use of hospital formularies in the UK. British fournal of Pharmaceutical Practice 1979;1:12-25.

22 Ridley H. Drugs of choice. A report on the drug formularies used in NHS hospitals. London: Social Audit, 1986.

23 Crooks J. Methods of "audit" in drug use. In: Duchênne-Marullaz P, ed. Advances in pharmacology and therapeutics. Vol 6. Clinical pharmacology. Oxford: Pergamon Press, 1978:189-95.

24 Barrett CW, Wilson AR, Baker JA. Formularies. In: Lawson DH, Richards RME, eds. Clinical pharmacology and hospital drug management. London: Chapman and Hall, 1982:335-53

25 Turner P. Local formularies and good patient care. Br Med f 1984;288:348.

26 Collier J, Foster J. Management of a restricted drugs policy in hospital: the firs five years' experience. Lancet 1985; i:331-3.

27 Tognoni G. A therapeutic formulary for Italian general practitioners. Lancet $1978 ; \mathrm{i}: 1352-3$.

28 Grant GB, Gregory DA, Van Zwanenberg TD. Development of a limited formulary for general practice. Lancet $1985 ; \mathrm{i}: 1030-2$.

29 Harding JM, Modell M, Freudenberg J, et al. Prescribing: the power to set limits. Br Med f 1985;290:450-3.

30 Anonymous. Local formularies - the way ahead (Editorial). Lancet 1986; ii: $1078-9$.

31 Petrie JC, Scott AK. Drug formularies in hospitals. Br Med $\mathcal{J}$ 1987;294: 919-20.

32 Plumridge RJ. Intervention strategies aimed at modifying prescribing behaviour. Australian fournal of Hospital Pharmacy 1984;14:93-100.

33 Anonymous. Secretary of State limits range of prescribable NHS drug [Editorial]. Br Med f 1984;289:1388-9.

34 Avorn J, Chen M, Hartley R. Scientific versus commercial sources of influence on the prescribing behaviour of physicians. Am $\mathcal{F}$ Med 1982;73:4-8.

35 Hemminki E. Review of literature on the factors affecting drug prescribing. Soc Sci Med 1975;9:111-6.

36 Mitchell MW, Fowkes FGR. Audit reviewed: does feedback on performance change clinical behaviour? I $R$ Coll Physicians Lond 1985;19:251-4.

37 Jones SR, Barks J, Bratton T, et al. The effect of an educational program upon hospital antibiotic use. Am 7 Med Sci 1977;273:79-85.

38 Merton and Sutton Health Authority/CASPE Research. The effect on drug prescribing of introducing a formulary and information service to clinicians. S Helier Hospital 1980-1983. London: CASPE Research, King Edward's Helier Hospital $1980-19$

39 Wickings I, Coles JM, Flux R, Howard L. Review of clinical budgeting and costing experiments. Br Med f 1983;286:575-8.

40 Nuffield Foundation. Pharmacy. The report of a committee of inquiry appointed by the Nuffield Foundation. London: Nuffield Foundation, 1986:64-7.

(Accepted 3 fune 1988)

\section{MATERIA NON MEDICA}

\section{Turkish delights}

Halicarnassus still exists, site of the mausoleum, seventh wonder of the ancient world. Now it is called Bodrum, a pleasant little seaside town in Turkey. Presiding over it is the great castle of the Knights Hospitallers, who later graduated to be the Knights of St John.

While on one of the popular boat excursions along the coast from Bodrum we noted that one of the crew stood out from the rest by his blue eyes and fair freckled complexion. He had a broad infectious grin, exposing a row of carious teeth, and a cheerfulness that compensated for his very rudimentary English. Was he perhaps the product of a Nordic knight's long forgotten indiscretion? We did not inquire, and he might not have known.

Within the castle walls marine archaeology features prominently as a permanent exhibition. Among the wooden Greek ships of the pre-Christian era, found at the bottom of the sea, one was carrying a humdrum deck cargo of sea anchors. Another, more interestingly, had a consignment of broken glass, presumably for resmelting. It seems that our new thoughts on recycling are less new than we are led to believe.

Up the coast, on the site of the once affluent ancient sea port of Miletus, stands a mediaeval mosque, abandoned and forlorn. In sympathy with the surrounding fields its cupola is green with grass, and storks' nests perch on its prominences. Within the imposing ill lit interior one may discern an ornamental frieze incorporating a champagne glass design. Doubtless this was an inadvertent introduction of an alcoholic theme into a strictly abstemious place of worship. Could this subtle irreverence have been a contributing factor to the present desolation? It may be fanciful to speculate along such lines.

As for the seventh wonder, we had been warned not to expect much from the remains of a monument that had successfully seen out 22 centuries. We saw some scattered fluted white marble drums and other assorted bits of masonry and a huge hole in the ground. It seems that when building material was required to shore up the walls of the castle the monument was the most convenient quarry available. Its marble, sculpture, and stone were mined down to its foundations. Only the drain at the bottom was left intact, as a gesture to posterity perhaps.

But stone is only stone; it is people who really matter, and they could not have been kinder. The local restaurateur did overdo it a little when he kissed me warmly on both cheeks. This I could not attribute, even after some anxious reflection, to either my physical beauty or even my charm. But then kissing is a part of the culture, and I was touched to see in the street a young man kissing the hand of an old lady.

Towards the end of our stay the thought occurred that some good Turkish figs might be medicinally useful. What was on offer, however, looked to be hard, shrivelled, and dry. What do you expect? we were asked. The good ones are all for export.-K G HEYMANN, London. 